- The majority of the sample were referred to specialist palliative care teams in their last week(s) of life

- Access to formal supports and care packages varied throughout the country.

Future plans A report will be made available online with the findings of this audit. This includes recommendations for people with dementia, for family members, for staff and for service planners. Information will also be shared with all of the specialist palliative care teams.

\section{P-138 LOSS AND GRIEF IN DEMENTIA}

Deirdre Shanagher, Sarah Cronin, Marie Lynch. Irish Hospice Foundation, Dublin, Ireland

10.1136/bmjspcare-2016-001245.161

Background A range of losses occur throughout a person's journey with dementia. Losses occur for the person and for their families as the disease progresses. Grief as a result of these losses is under-recognised and under-reported by people with dementia and their families.

Aim To develop a guidance document and factsheet to support healthcare staff to recognise, acknowledge and respond to loss and grief in dementia.

Methods An Expert Advisory Group (EAG) was convened. The group followed the NCEC approach to developing clinical guidance which included literature reviews, consensus building and consultation with key stakeholders.

Results The guidance document and factsheets are available to support healthcare staff in working with loss and grief in dementia. The document has four key considerations for staff to use as good practice when working with loss and grief in dementia. These are followed by four guidance areas which are responding to loss and grief, supporting the person with dementia experiencing loss and grief, supporting families with loss and grief and supporting yourself as a healthcare staff member. Resources will be listed for each of these areas.

Conclusion Recognising loss and grief as part of the experience of having dementia is a core part of good dementia care. Provision of supports to people and their families at transition points is essential.

Future plans This guidance document is one in a suite of seven guidance documents developed relating to different aspects of dementia palliative care. A dissemination plan has been developed to ensure findings and guidance are implemented and evaluated.

\section{P-139 CREATING A DEMENTIA FRIENDLY HOSPICE \& COMMUNITY CORPORATE PARTNERS}

Michelle Baskerville, Suzi Smith, Louise Eagle. Douglas Macmillan Hospice, Stoke on Trent, UK

\subsection{6/bmjspcare-2016-001245.162}

In 2015 the Douglas Macmillan Hospice launched a project to become dementia friendly as we are supporting more patients with a primary or secondary diagnosis of dementia. Staff undertook the Dementia Friends Champion training and to date we have over 300 dementia friends, staff and volunteers, throughout the hospice and retail outlets.

A cross-hospice working party is evaluating and adapting the hospice environment ensuring it is accessible to those who are living with dementia. This has led to further discussions and adaptations for all those who have a disability.

Our in-patient facilities and community teams have implemented a Pain Scale Tool to ensure those living with dementia, who are unable to communicate verbally, have their pain effectively managed.

The hospice is engaged with local and national forums to share best practice and to shape and support the local community in becoming dementia friendly.

Creating dementia friendly community corporate partners: In January 2016 we launched the opportunity for our corporate partners to engage with the hospice in an entirely new way. As a way of the hospice giving something back for their support we offered to deliver Dementia Friends training to local companies and their staff. We have sessions booked to create Dementia Friends in our community with Hanley Economic Building Society and other hospice corporate partners.

Case study: Stoke City Football Club Stoke City Football Club have supported the hospice for a number of years, they received the highest Corporate Award the hospice offers and became a Platinum Corporate Partner for contributions made throughout 2015. Since we launched the scheme to our corporate partners over 80 members of staff at the football club have become Dementia Friends. The club is now aiming to become one of the first Dementia friendly football clubs with the support of the Douglas Macmillan Hospice.

\section{P-140 'LOCAL PEOPLE HELPING LOCAL PEOPLE': A TEENAGER'S CONTRIBUTION TO DEMENTIA FRIENDLY SWAY}

${ }^{1}$ Sophie Russell, ${ }^{2}$ Stephen Tarling, ${ }^{3}$ Fiona Willis, ${ }^{3}$ Sarah Russell. ${ }^{1}$ Talbot Heath School, Bournemouth, UK; ${ }^{2}$ Sway Parish Council, Hampshire; ${ }^{3}$ Dementia Friendly Sway Volunteer Action Group

\subsection{6/bmjspcare-2016-001245.163}

Background In the UK there are around 800,000 people with dementia. Dementia friendly communities are places where more people understand dementia and people are supported to live well. Sway is a small village in the New Forest (population 3548). One of Sway Parish Council's strategic objectives is to help ageing people live well. As a carer and as part of her Duke of Edinburgh Bronze Award this abstract describes a 15 -year-old's activity in supporting the parish council's strategic objective.

Aims

- To support people with dementia and their carers: 'Local People Helping Local People,

- To connect and collaborate with other local groups: 'Helping People Live Well'.

Method

- Dementia Friends sessions to parish council, girl guide groups, churches, interest groups, care homes and agencies as well as businesses (e.g. hairdresser, gardeners, and postmen)

- Role-modelling dementia friendly attitudes and behaviour (e.g. there is more to a person than dementia) in village activities, Saturday job in local coffee shop and monthly dementia friendly coffee and chat group

- Information animations to raise awareness

- Providing a teenager's perspective to local volunteer action group. 